\title{
Consonant discrimination by Mandarin-speaking children with prelingual hearing impairment
}

\author{
Shufeng Zhu ${ }^{\text {a,b) }}$, Lena L. N. Wong ${ }^{\text {b) }}$, Fei Chen ${ }^{\text {a,b) }}$ and Yuan Chen ${ }^{\text {b) }}$
}

a) Department of Electrical and Electronic Engineering, South University of Science and Technology of China, Shenzhen

b) Division of Speech and Hearing Sciences, the University of Hong Kong, Hong Kong

Source of Funding: This research was funded by the Faculty Research Fund, administered by the Faculty of Education, the University of Hong Kong as well as the General Research Fund \# 780109, administered by the Hong Kong Research Grants Council (RGC).

Address correspondence to:

Ms. Shufeng Zhu

Department of Electrical and Electronic Engineering

South University of Science and Technology of China

No. 1088 Xueyuan Blvd., Shenzhen, China

Email: shufengzhu01@gmail.com

Tel: 86-15712038178, 852-53447063 


\begin{abstract}
Objectives: Little is known about the consonant discrimination ability of Mandarin-speaking children with prelingual hearing impairment (HI) and fitted with hearing aids (HAs). The present study aimed to evaluate Mandarin consonant discrimination ability in children with HI, and explore the effects of unaided and aided hearing threshold, the age of first HA fitting and the duration of HA use on consonant discrimination ability.
\end{abstract}

Methods: Subjects were Mandarin-speaking children aged 5;4 to $12 ; 6$ years with profound HI $(n=41)$, children aged $6 ; 1$ to $12 ; 4$ years with severe $\mathrm{HI}(\mathrm{n}=26)$, and children aged $5 ; 0$ to $11 ; 9$ years with moderate HI $(n=9)$. The Mandarin consonant discrimination test was administered in six test conditions: $-10,-5,0,5$ and $10 \mathrm{~dB}$ signal to noise ratios (S/Ns) and quiet. HAs were in the usual user's settings, adjusted to match the manufacturer prescribed settings and individual preferences, and the volume was set to comfortable listening level.

Results: The results revealed that $/ \mathrm{p}^{\mathrm{h}} /-/ \mathrm{th}^{\mathrm{h}} /, / \mathrm{ts} /-/ \mathrm{ts} /$ and $/ \mathrm{z} /-/ \mathrm{l} /$ were the most difficult and $/ \mathrm{p} /-/ \mathrm{p}^{\mathrm{h}} /, / \mathrm{t} /-/ \mathrm{t}^{\mathrm{h}} /, / \mathrm{t} 6 /-/ \mathrm{t}^{\mathrm{h}} /$ and $/ \mathrm{k} /-/ \mathrm{k}^{\mathrm{h}} /$ were the easiest consonant minimal pairs to discriminate in quiet both for children with profound $\mathrm{HI}$ and those with moderate to severe HI. In noise, no significant difference in performance was found among all consonant minimal pairs. A backward elimination stepwise multiple linear regressions revealed that unaided hearing level accounted for $25.4 \%$ of the variance in consonant discrimination performance in noise at $10 \mathrm{~dB}$ $\mathrm{S} / \mathrm{N}$ and $30.4 \%$ in quiet. However, aided hearing threshold, the age of first HA fitting and the duration of HA use did not significantly predict consonant discrimination ability both in quiet and in noise. 
Conclusions: Consonant discrimination performance of children with profound HI was poorer than those with moderate to severe HI. The ability to discriminate consonant pairs seems to depend on age of acquisition of the consonants. Although the age of first HA fitting and the duration of HA use were not correlated with consonant discrimination outcomes, this finding does not preclude the importance of early HA fitting.

Key Words: Mandarin consonant discrimination, hearing in noise, hearing loss, hearing aids

\begin{abstract}
Abbreviations:
BEPTA =better ear hearing threshold averaged; $\mathrm{CI}=$ cochlear implant; $\mathrm{HI}=$ hearing impairment; $\mathrm{H}-$ NTLA=Hiskey-Nebraska Test of Learning Aptitude; MCDT=Mandarin Consonant Discrimination Test; $\mathrm{NH}=$ normal-hearing; $\mathrm{S} / \mathrm{N}=$ signal to noise ratio; $\mathrm{SSN}=$ speech spectrum shaped noise
\end{abstract}




\section{Introduction}

A large amount of evidence has indicated that consonants play an important role in speech perception [1-4]. For example, Woods et al. [4] and Grant et al. [5] found a strong relationship between consonant identification and sentence perception of adults with normal hearing (NH) and with HI, respectively. Phillips, Richter and McPherson [2] also found that voiced initial consonant identification ability is well correlated with word perception ability in older listeners with hearing impairment (HI), and good initial voiced consonant identification ability leads to good word perception ability. Although Chen et al. [6] also found Mandarin consonant contributed to speech perception ability for adults with $\mathrm{NH}$, few research has reported consonant perception in Mandarin speaking children with HI

There are 21 Mandarin consonants classified into five categories according to the manner of articulation. The plosives consist of $/ \mathrm{p}, \mathrm{p}^{\mathrm{h}}, \mathrm{t}, \mathrm{t}^{\mathrm{h}}, \mathrm{k}, \mathrm{k}^{\mathrm{h}} /$, the nasals include $/ \mathrm{m}, \mathrm{n} /$, the fricatives compose of / f, s, $s, z_{e}, 6, x /$, the affricates comprise $/ t s, \mathrm{ts}^{\mathrm{h}}, \mathrm{ts}, \mathrm{t} \mathrm{s}^{\mathrm{h}}, \mathrm{t} 6, \mathrm{t} 6^{\mathrm{h}} /$ and finally, one have the lateral approximant /1/. According to the place of articulation, these 21 consonants can also be divided into bilabial $\left(/ \mathrm{p}, \mathrm{p}^{\mathrm{h}}, \mathrm{m} /\right)$, labiodental $(/ \mathrm{f} /)$, alveolar $\left(/ \mathrm{t}, \mathrm{t}^{\mathrm{h}}, \mathrm{s}, \mathrm{ts}, \mathrm{ts} \mathrm{s}^{\mathrm{h}}, \mathrm{n}, \mathrm{l} /\right)$, palate-alveolar $(\mathrm{s}$, ts, $\left.\mathrm{ts}^{\mathrm{h}}, \mathrm{z} /\right)$, palatal $\left(/ 6, \mathrm{t} 6, \mathrm{t}^{\mathrm{h}} /\right)$ and velar $\left(/ \mathrm{k}, \mathrm{k}^{\mathrm{h}}, \mathrm{x} /\right)$ consonants [7]. The six plosives and six affricates are further categorized as aspirated $\left(/ \mathrm{p}^{\mathrm{h}}, \mathrm{t}^{\mathrm{h}}, \mathrm{k}^{\mathrm{h}}, \mathrm{ts}^{\mathrm{h}}, \mathrm{ts}^{\mathrm{h}}, \mathrm{t} 6^{\mathrm{h}} /\right)$ and unaspirated $(/ \mathrm{p}, \mathrm{t}, \mathrm{k}, \mathrm{ts}, \mathrm{ts}, \mathrm{t} 6 /)$ consonants, with aspiration being produced as a breathy noise generated by the air getting through the subglottal area during the period between its release and the emergence of the subsequent vowel [8]. The only phonemes in Mandarin distinguished by voicing are the two fricatives /s/ and / $\mathrm{zl}$. 
Lin and Peng [9] evaluated consonant identification ability of Mandarin-speaking children with cochlear implants (CIs). These children were on average 9;3 years of age and were implanted at an average age of 5;8 years. A total of 16 consonant minimal pairs made from the 21 Mandarin consonants were created based on the distinctive features of consonants, i.e., manner of articulation, place of articulation, aspiration and voicing. Seven consonant minimal pairs $\left(/ \mathrm{t} 6 /-/ \mathrm{t}_{6}^{\mathrm{h}} /, / \mathrm{s} /-/ \mathrm{s} /\right.$, $/ \mathrm{p}^{\mathrm{h}} /-/ \mathrm{t}^{\mathrm{h}} /, / \mathrm{ts} /-/ \mathrm{ts}^{\mathrm{h}} /, / \mathrm{ts}^{\mathrm{h}} /-/ \mathrm{ts}^{\mathrm{h}} /, / \mathrm{n} /-/ \mathrm{l} /$ and $/ \mathrm{ts} /-/ \mathrm{ts} /$ ) scored below $75 \%$, six pairs scored from $76 \%$ to $89 \%$ and the other three pairs scored at least $90 \%$. Although the authors did not explain why these seven pairs were more difficult, six pairs exhibited similar formant characteristics $\left(/ \mathrm{t}_{6} /-\right.$ $/ \mathrm{t}_{6}^{\mathrm{h}} /, / \mathrm{s} /-/ \mathrm{s} /, / \mathrm{ts} /-/ \mathrm{ts}^{\mathrm{h}} /, / \mathrm{ts}^{\mathrm{h}} /-/ \mathrm{ts}^{\mathrm{h}} /, / \mathrm{n} /-/ \mathrm{l} /$ and $\left./ \mathrm{ts} /-/ \mathrm{ts} /\right)$ [10]. Four $\left(/ \mathrm{t} 6 /-/ \mathrm{t} \mathrm{c}^{\mathrm{h}} /, / \mathrm{ts} /-/ \mathrm{ts}^{\mathrm{h}} /\right.$, $/ \mathrm{ts}^{\mathrm{h}} /-/ \mathrm{ts}^{\mathrm{h}} /$, and $\left./ \mathrm{ts} /-/ \mathrm{ts} /\right)$ of the seven pairs were affricates, which are the most difficult category for children with $\mathrm{NH}$ to acquire $[11,12]$. Hence, it is not unexpected that these consonant minimal pairs are more difficult for children with CIs to identify.

Using 15 of the same minimal pairs as in Lin and Peng [9], Zhang and Xu [13] found that Mandarin-speaking children with $\mathrm{NH}$ aged six could identify these consonants with at least $90 \%$ accuracy. However, for children with $\mathrm{NH}$ aged six and children with $\mathrm{CI}$ aged about nine, /ts/-/ts/ was the most difficult consonant minimal pair, scoring slightly below $90 \%$. The above two studies showed that children with CI performed much poorer than those with $\mathrm{NH}$ in quiet. It is not surprising that the performance of children with CI are poorer because electric stimulation mainly provides harsh spectral cues [14,15] and temporal envelope cues [16]. Meanwhile, children in Lin and Peng's study received CIs at a late age (mean $=5 ; 8$ years) causing a delay in language development [17]. As there are differences in how auditory signals are being processed and how 
the ear is being stimulated in hearing aid users, these findings are not readily applicable to Mandarin-speaking children fitted with HAs.

Various factors may affect consonant discrimination. These include the degree of HI, the aided hearing threshold, age of first HA fitting and duration of HA use. Erber [18] found that the consonant discrimination ability reduced with poor hearing thresholds: near perfect consonant discrimination ability was found among English speakers with $\mathrm{NH}$, while those with severe $\mathrm{HI}$ performed poorly; whereas poorest performance was noted in those with profound $\mathrm{HI}$; even when audibility was compensated for. Early implantation $[19,20]$ and longer CI use [21] have been found to relate to better speech perception ability in Mandarin-speaking children with prelingual HI. Many studies also reported that age of first CI fitting and duration of CI use importantly influence consonant discrimination ability on children with CIs $[9,22]$. However, little is known about the effects of age of first HA fitting and duration of HA use on Mandarin consonant discrimination ability. Therefore, the present study evaluated 1) Mandarin consonant discrimination ability in children with different levels of HI and wear HAs, and 2) the effects of aided hearing threshold, age of first HA fitting and duration of HA use on Mandarin consonant discrimination ability.

\section{Materials and methods}

\subsection{Subjects}

A convenience sample of 41 children with profound HI (17 females and 24 males), 26 children with severe HI (13 females and 13 males) and nine children (three females and six males) with moderate HI were recruited. The pediatric clientele of the Hearing Impairment and Rehabilitation Institute of Zhejiang Chinese Medical University in Hangzhou were contacted and these children 
represented all those willing to participate in the present research. Among the 81 children, all participants speak standard Mandarin as their native Chinese dialect. Table 1 and 2 list the details of these three groups. Participants were classified according to the WHO criterion: profound group included those with better ear hearing threshold averaged (BEPTA) at 500, 1000, 2000 and 4000 $\mathrm{Hz}$ above $80 \mathrm{~dB} \mathrm{HL}$, the severe group consisted of those whose with BEPTA between 61 and 80 $\mathrm{dB}$ HL and the moderate group composed of those with BEPTA between 41 and $60 \mathrm{~dB}$ HL [23]. The severe and profound HI groups exhibited mostly sloping configuration and the moderate HI group exhibited mostly flat hearing loss bilaterally. They were all bilaterally fitted with HAs that were in users' usual settings during testing. That is, the HAs were adjusted to match manufacturers' prescribed settings, and modified to optimize auditory perception, according to feedback from the participants, parents and/or teachers. They all used omnidirectional microphones and no noise reduction schemes. More than half of participants (58\%) had not received rehabilitation training. All participants had normal cognitive abilities, achieving scores above 84 on a non-verbal intelligence test Hiskey-Nebraska Test of Learning Aptitude (H-NTLA) [24,25]. This study was approved by the Human Research Ethics Committee for Non-Clinical Faculties of the University of Hong Kong.

Insert Table 1 and 2

\subsection{Materials}

Test materials included the non-verbal intelligence test H-NTLA, which was validated on children with NH and HI aged from 3 to 18 [24-26] and the Mandarin Consonant Discrimination Test (MCDT). The MCDT was developed in the current study to evaluate consonant discrimination ability in quiet and in noise because currently available consonant perception test materials (e.g., 
Zheng et al. [27]; Lin \& Peng [9]) are administered in quiet and did not fit the purposes of the current research (i.e., evaluation of consonant discrimination ability in quiet and noise). In addition, the Mandarin Early Speech Perception Test (MESP) contains two few (12) test stimuli in Zheng et al. [27] and therefore the test may not be sensitive in indicating a range of performance. The consonant identification test described by Lin and Peng evaluates consonant perception in minimal contrastive pairs based on distinctive features of consonants (see Table 3). This test may be too difficult for the participants in the current study, who exhibited severe HI and fitted with HAs late and thus were expected to perform poorer than those fitted with CIs [28-30]. Therefore, the present study employed the test materials in Lin and Peng and presented them in a discrimination task, which should be easier than an identification test [31].

Insert Table 3

A male adult speaking standard Mandarin spoke the test stimuli three times. Two native standard Mandarin-speaking adults selected the most naturally spoken recording among the three. The Matlab program was used to measure and equate the root-mean-square (RMS) value of each word. Speech Spectrum-shaped Noise (SSN) was used as the masker to corrupt the test stimuli at different signal-to-noise levels. A finite impulse response filter was designed based on the average spectrum of the testing words, and white noise was filtered and scaled to the same long-term average spectrum and level as the words. To avoid the effect of co-articulation of the carrier phrase on the test stimuli [32], the stimuli and the carrier phrase were recorded separately. These signals were then spliced, with a one-second pause in between. In the noise conditions, the noise was presented together with the speech, at the designated levels. 


\subsection{Equipment}

The test was performed in a sound-treated room with noise level lower than $35 \mathrm{~dB}$ A. The test words of MCDT were recorded using an AKG C3000B microphone, located $20 \mathrm{~cm}$ away from the speaker, at a sampling rate of $48 \mathrm{kHz}$. All test words were recorded in a sound treated room. The test stimuli were presented in random order using the custom program and presented via a pair of Creative Gigaworks T40 2.0 loudspeakers, placed at 0 (signals) and 180 (noise) degrees azimuths, respectively.

\subsection{Procedures}

A custom program was developed to conduct and score the consonant discrimination test. The noise level was calibrated to $65 \mathrm{~dB}$ A at 1 meter away from the center of the head of participants, and the speech stimuli were adjusted to yield the appropriate $\mathrm{S} / \mathrm{N}$ levels. The S/Ns for evaluating children with $\mathrm{HI}$ were set at $-10,-5,0,5$ and $10 \mathrm{~dB}$. These $\mathrm{S} / \mathrm{Ns}$ should result in performance in the linear portion of the PI function. In quiet, the stimuli were delivered at a fixed level of $65 \mathrm{~dB}$ (A).

Subjects were introduced to the program and practiced before the actual test. Each minimal pair was presented three times, resulting in a total of 48 test sets $(=16$ consonant minimal pairs $\times$ 3 test sets). The order of these 48 test sets was randomized. The listener was asked to indicate whether the two stimuli were the same. by tapping the " $\checkmark$ "symbol or different by tapping the “ $X$ "symbol on a 12-inch touch screen. Participants were given five seconds to respond, after which the next word presentation stream would follow. A nil response would be considered as a 
wrong answer.

\section{Results}

\subsection{Consonant discrimination ability}

Figure 1 shows that performance increased as $\mathrm{S} / \mathrm{N}$ improved. The data met all the assumptions of one-way ANOVA, which showed a significant difference in performance among the three hearing loss groups across all test conditions $(p<0.001)$. Post hoc Tukey test showed significant differences in consonant discrimination between children with profound HI and children with moderate $\mathrm{HI}$ in all test conditions $(p s<0.05)$ except at $-10 \mathrm{~dB} \mathrm{~S} / \mathrm{N}$. In addition, significant differences were found between children with profound $\mathrm{HI}$ and children with severe $\mathrm{HI}$ among all the test conditions $(p s<0.05)$ except at $-10 \mathrm{~dB} \mathrm{~S} / \mathrm{N}$. However, no significant differences in consonant discrimination were noted between children with moderate $\mathrm{HI}$ and children with severe $\mathrm{HI}$ in all test conditions ( $p s>0.05)$.

Insert Figure 1

Two-way repeated measures ANOVA was conducted to examine the effects of the six test conditions (i.e., quiet and five $\mathrm{S} / \mathrm{N}$ levels) and 16 consonant minimal pairs. Mauchly's test indicated that the assumption of sphericity was violated, $\chi^{2}(14)=100.8, p>0.05$; therefore the degree of freedom was corrected using Greenhouse-Geisser estimates of sphericity ( $\varepsilon=.5)$. Twoway repeated measures ANOVA analysis showed a significant effect of test conditions on consonant discrimination ability, $F(2.5,101.1)=45.18, p<0.001$. Post hoc pairwise comparisons showed significant differences in consonant discrimination among all the six test conditions $(p s<0.001)$. 
Furthermore, significant interactions were noted between the six test conditions and the 16 consonant minimal pairs, $F(24.0,958.3)=1.6, p<0.05$. One-way repeated measures ANOVA was conducted in each test condition to further analyze the significant interaction effect. Significant differences were noted in the discrimination of the 16 consonant minimal pairs in quiet only $(p<0.001)$. Figure 2 shows the average percent correct discrimination scores for the 16 consonant minimal pairs of children with profound $\mathrm{HI}$ children in quiet. The scores of four consonant minimal pairs $\left(/ \mathrm{p}^{\mathrm{h}} /-/ \mathrm{t}^{\mathrm{h}} /, / 6 /-/ \mathrm{s} /, / \mathrm{ts} /-/ \mathrm{ts} /\right.$ and $\left./ \mathrm{z} /-/ \mathrm{l} /\right)$ were one SD lower than the average score in quiet and the score of four pairs $\left(/ \mathrm{p} /-/ \mathrm{p}^{\mathrm{h}} /, / \mathrm{t} /-/ \mathrm{t}^{\mathrm{h}} /, / \mathrm{t} 6 /-/ \mathrm{t}^{\mathrm{h}} /\right.$ and $\left./ \mathrm{k} /-/ \mathrm{k}^{\mathrm{h}} /\right)$ were one SD higher than the average score in quiet.

Insert Figure 2

As there was no significant difference in consonant discrimination performance between children with moderate and severe $\mathrm{HI}$ in each test condition, results from these two groups were merged for further data analyses. There was another reason to support this move. The difference between the average aided hearing thresholds of severe $\mathrm{HI}(34.1 \pm 7.5 \mathrm{~dB} \mathrm{HL})$ and moderate $\mathrm{HI}$ (30.2 $\pm 4.9 \mathrm{~dB} \mathrm{HL})$ was only about $3.9 \mathrm{~dB}$ HL. Therefore, it was reasonable to combine subjects with moderate and severe $\mathrm{HI}$ as one group in the current study. Two-way repeated measures ANOVA analysis was conducted to examine the effects of the six test conditions and the 16 consonant minimal pairs. Mauchly's test indicated that the assumption of sphericity was violated for the main effect of test conditions, $\chi^{2}(14)=77.9, p<0.001$; therefore the degree of freedom was corrected using Greenhouse-Geisser estimates of sphericity $(\varepsilon=.5)$. Two-way repeated measures ANOVA analysis showed that there was a significant effect of test conditions on consonant discrimination ability, $F(2.5,85.1)=58.1, p<0.001$. Post hoc pairwise comparisons showed significant difference among all the six test conditions $(p s<0.01)$. 
Significant interactions were noted between the six test conditions and the 16 consonant minimal pairs, $F(22.0,748.8)=1.6, p<0.01$. One-way repeated measures ANOVA was conducted on results obtained in each test condition to further analyze the interaction effects. Again, significant differences in the discrimination of the 16 consonant minimal pairs were noted in quiet only $(p<0.001)$. Figure 3 shows the average percent correct discrimination scores for the 16 consonant minimal pairs obtained in children with moderate to severe HI in quiet. The scores of five consonant minimal pairs $\left(/ \mathrm{p}^{\mathrm{h}} /-/ \mathrm{t}^{\mathrm{h}} /, / \mathrm{s} /-/ \mathrm{s} /, / \mathrm{z} /-/ \mathrm{l} /, / \mathrm{n} /-/ \mathrm{l} /\right.$ and $\left./ \mathrm{ts} /-/ \mathrm{ts} /\right)$ were one SD lower than the average score in quiet and the score of four pairs $\left(/ \mathrm{t} /-/ \mathrm{t}^{\mathrm{h}} /, / \mathrm{f} /-/ \mathrm{x} /, / \mathrm{t}_{6} /-/ \mathrm{t}^{\mathrm{h}} /\right.$, $/ \mathrm{p} /-/ \mathrm{p}^{\mathrm{h}} /$ and $/ \mathrm{k} /-/ \mathrm{k}^{\mathrm{h}} /$ ) were one SD higher than the average score in quiet.

\section{Insert Figure 3}

In summary, the consonant discrimination performance of children with profound HI was significantly lower than children with moderate to severe $\mathrm{HI}$ and the performance increased as $\mathrm{S} / \mathrm{N}$ improved. For children with moderate to severe HI, $/ \mathrm{p}^{\mathrm{h}} /-/ \mathrm{t}^{\mathrm{h}} /, / \mathrm{s} /-/ \mathrm{s} /, / \mathrm{z} /-/ \mathrm{l} /, / \mathrm{n} /-/ \mathrm{l} /$ and $/ \mathrm{ts} /-$ /ts / were more difficult and $/ \mathrm{t} /-/ \mathrm{t}^{\mathrm{h}} /, / \mathrm{f} /-/ \mathrm{x} /, / \mathrm{t} 6 /-/ \mathrm{t}^{\mathrm{h}} /, / \mathrm{p} /-/ \mathrm{p}^{\mathrm{h}} /$ and $/ \mathrm{k} /-/ \mathrm{k}^{\mathrm{h}} /$ were easier for them to discriminate compared with other consonant minimal pairs in quiet. For children with profound HI, $/ \mathrm{p}^{\mathrm{h}} /-/ \mathrm{t}^{\mathrm{h}} /, / 6 /-/ \mathrm{s} /, / \mathrm{ts} /-/ \mathrm{t} \mathrm{s} /$ and $/ \mathrm{z} /-/ \mathrm{l} /$ were more difficult and $/ \mathrm{p} /-/ \mathrm{p}^{\mathrm{h}} /, / \mathrm{t} /-/ \mathrm{t}^{\mathrm{h}} /$, $/ \mathrm{t} 6 /-/ \mathrm{t}^{\mathrm{h}} /$ and $/ \mathrm{k} /-/ \mathrm{k}^{\mathrm{h}} /$ were easier for them to discriminate compared with other consonant minimal pairs in quiet. However, in noisy conditions, no significant difference in performance was found among all consonant minimal pairs, whether children with profound $\mathrm{HI}$ or those with moderate to severe $\mathrm{HI}$ were concerned.

\subsection{Factors influencing consonant discrimination ability}


Figure 4 shows the mean scores of consonant discrimination test in quiet and in five noisy conditions across all children. These results help to identify the $\mathrm{S} / \mathrm{N}$ where the PI function slope is the steepest, where maximum sensitivity in performance and reliability are expected [33]. However, in noise, only the performance at $10 \mathrm{~dB} \mathrm{~S} / \mathrm{N}$ above the chance level (67\%). Testing at $10 \mathrm{~dB} \mathrm{~S} / \mathrm{N}$ seems to be a better choice to represent performance in noise.

Insert Figure 4

To evaluate the effects of four factors (i.e., unaided hearing threshold, aided hearing threshold, age of first fitting HA, and duration of HA use) on consonant discrimination both in quiet and in noise, a backward stepwise regression was applied to remove dependent variables with the smallest partial correlation, step by step. Results revealed that the unaided hearing threshold accounted for $25.4 \%$ of the variance in consonant discrimination scores obtained at $10 \mathrm{~dB} \mathrm{~S} / \mathrm{N}$ and $30.4 \%$ in quiet (see Table 4).

Insert Table 4

\section{Discussion}

\subsection{Factors influencing consonant discrimination ability}

The present study revealed that the level of unaided hearing thresholds significantly predicted consonant discrimination performance both in quiet and in noise, although this factor only accounted for a small proportion of variances of performance. The current study indicated that the consonant discrimination ability of children with moderate to severe HI was significantly better than those with profound HI both in noise and in quiet, which is consistent with previous findings that speech perception ability declines as the degree of HI increases [18,34,35]. In previous research, unaided hearing thresholds were also found significantly correlated with consonant perception in English-speaking children with HI [18]. Consonant discrimination performance of 
children with $\mathrm{HI}$ in noise was significantly poorer than that in quiet. However, there is no difference in performance across the 16 minimal pairs evaluated in noise in the present study probably due to two reasons. First, SSN which was used in the present study was an effective energetic masker which overlaps spectrally with speech signals. It seems to have caused a masking effect that is equally effective on all consonant minimal pairs. Therefore, the performance in noise was around or slightly above the chance level. Second, to reduce Type I error, the p-value was adjusted by the number of comparisons, with an impact that the null hypothesis may not be rejected when it is false (Type 2 error).

However, in the present study, aided hearing thresholds did not relate to consonant discrimination ability. Previous research [36-38] also reported that mean speech perception scores do not differ greatly among those with aided hearing thresholds between 35 to $45 \mathrm{~dB}$ HL. As the aided hearing thresholds in the current study ranged from 26 to $50 \mathrm{~dB}$ HL (averaged at $39 \mathrm{~dB} \mathrm{HL}$ ) among children with HI, our findings are therefore consistent with those from previous research.

The current results also indicated that the age of first HA fitting and duration of HA use were not significant predictors. This result is consistent with that reported in Mandarin-speaking children wearing CIs Peng et al. [39] and with HAs Zhu et al. [40]. In contrast, Zhou et al. [21] and Chen et al. [20] reported that the age of first HA fitting and the duration of HA use were related to speech perception. Three reasons might have contributed to these differences. First, hearing devices used in these researches were different. While HAs were used in the current research and that of Zhu et al. [40], CIs were used in the other three. Secondly, the mean duration of device use differed, with subjects in Zhou et al and Chen et al having used hearing devices for an average of 
16 and 20 months respectively. In comparison, the duration of device use in the studies (current study, Peng et al. [39] and Zhu et al. [40]) that did not show effects of age of first HA fitting and duration of use being much longer (ranged from 43 to 76 months). As indicated by Connor [41], consonant production of children with CI accelerates immediately after implantation and the rate of upward trajectory slow down after several years. It is possible that, consonant discrimination accuracies of the children who had obtained HAs might have developed at a higher growth rate initially such that their performances were correlated with their speech perception abilities. Third, compared to other studies with early HA fitting (6 to 12 months), children in these studies (current study, Peng et al. [39] and Zhu et al. [40]) received HAs late (32 to 68 months), which is typical of school-age children with HI in mainland China. Because of the variations in reported relationships among different studies, it is difficult to make conclusions regarding the effects of early hearing intervention. This is not to deny the benefits from early amplification but point to the need for further investigation.

\subsection{Consonant discrimination in quiet}

In quiet, three consonant minimal pairs $\left(/ \mathrm{p}^{\mathrm{h}} /-/ \mathrm{t}^{\mathrm{h}} /, / \mathrm{ts} /-/ \mathrm{ts} / \mathrm{c} /-/ \mathrm{s} /\right.$ and $/ \mathrm{s} /-/ \mathrm{s} /$ and $/ \mathrm{z} /-$ /l/)/were difficult to discriminate by children with moderate to severe and profound HI. The first four pairs contrast by place of articulation. The $/ \mathrm{z} /-/ \mathrm{l} /$ pair contrasts by both place of articulation and manner of articulation. The difficulty in discriminating these consonant minimal pairs may be attributed to the different place of articulation. According to Bamford and Saunders [42], place of articulation is the main error type for English consonant discrimination. Previous research also showed that Cantonese-speaking individuals with $\mathrm{HI}$ also have difficulty in identifying the consonants according to the place of articulation [43]. The authors put forward several reasons to 
explain the findings. Firstly, the intensity of consonants may be below or close to the aided hearing thresholds of the participants, such that audibility could be an issue. Secondly, listeners with HI may have more difficulties processing the rapid frequency changes related to formant transitions and release burst in comparison to listeners with NH [42]. Thirdly, listeners with HI may have abnormal representation of the phonetic categories for the place contrasts. The latter two reasons may partially explain the difficulty in discriminating the place contrasts by children with HI participated in the current study. Although these difficult contrastive pairs differ in place of articulation, other not so difficult contrastive pairs in the present study also differ by the same feature. Therefore, place of articulation alone may not determine the difficulties in consonant discrimination.

Children with moderate to severe HI also had difficulties in discriminating the $/ \mathrm{n} / \mathrm{-} / \mathrm{l} /$ contrast in quiet. Tse [44] also found lateral and nasal consonants were the most difficult to identify by normal hearing adults, among other manners of articulation. Compared with other Mandarin consonants, these phonemes $\left(/ \mathrm{p}^{\mathrm{h}} /-/ \mathrm{t}^{\mathrm{h}} /, / \mathrm{ts} /-/ \mathrm{ts} /, / \mathrm{z} /-/ \mathrm{l} /, / \mathrm{c} /-/ \mathrm{s} /, / \mathrm{s} /-/ \mathrm{s} /\right.$ and $\left./ \mathrm{n} /-/ \mathrm{l} /\right)$ are the last to be acquired by children with $\mathrm{NH}$ and are not expected to haven been mastered until they are about 4 or 5 years of age $[12,45]$. Given the fact that the participants in the present study obtained their HAs late (mean 3.6 years of age), these phonemes might not have been fully acquired by all, at the time of the study. As there is a lack of research on phoneme acquisition in Mandarin speaking children with HI, further research in this area is needed.

The results from the current study and Lin and Peng [9] were compared as both studies evaluated the perception of the same consonant contrasts and the participants in both studies were 
on average about 9 years of age. In the current study, children with moderate to severe HI obtained scores below $75 \%$ for four consonant minimal pairs in quiet (i.e., /s/-/s/, /z/-/l/, /n/-/l/ and /ts/-/ts/). Participants in Lin and Peng scored three of these consonant pairs (i.e., /s/-/s/, /n//l/ and /ts/-/ts/) below 75\%, in addition to $/ \mathrm{t} 6 /-/ \mathrm{t}^{\mathrm{h}} /, / \mathrm{p}^{\mathrm{h}} /-/ \mathrm{t}^{\mathrm{h}} /, / \mathrm{ts} /-/ \mathrm{ts}^{\mathrm{h}} /$ and $/ \mathrm{ts}^{\mathrm{h}} /-/ \mathrm{ts}^{\mathrm{h}} /$. The two contrastive minimal pairs /n/-/l/ and /ts/-/ts/ were the two most difficult in both studies. Overall, children with moderate to severe HI and use HAs in the present study performed better than those in Lin and Peng, which is not surprising as the discrimination task used in the present study required lower level listening skills than the identification task in Lin and Peng [18]. It is also reasonable that consonant discrimination is better among those with better hearing ability in the preset study although their mean aided hearing thresholds are quite comparable. As mentioned above, HAs preserve acoustic information better than CIs, whereas electric stimulation mainly provides harsh spectral cues $[14,15]$ and temporal envelope cues [16]. In addition, the average age of first CI use was 68 months in Lin and Peng, whereas the mean age of first HA use was 43 months in the current study. Although both groups received amplification late, those in the present study were able to use HAs 25 months earlier than those in Lin and Peng. The longer duration of HAs use may contribute to better consonant discrimination in the present study [21,22]. We must note here however that the comparison to findings in Lin and Peng could be confounded by inconsistency in stimuli presentation levels, visual cues and other associated factors on the results reported in Lin and Peng [9], due to the use of live voice in stimuli presentation method.

Among children with profound HI, five consonant pairs (i.e., /s/-/s/, /ts/-/ts $/$, /ts $/-/ \mathrm{ts}^{\mathrm{h}} /$, $/ \mathrm{p}^{\mathrm{h}} /-\mathrm{t}^{\mathrm{h}} /$ and $\left./ \mathrm{ts} /-/ \mathrm{ts} /\right)$ scored below $75 \%$ correct in both studies and six other pairs (i.e. /f//x/,/t/-/k/, /6/-/s/, /n/-/l/, /z/-/l/ and /p/-/m/) also scored below $75 \%$ in the current study. 
Although the discrimination task used in the present study is easier than the identification task in Lin and Peng [9] and HAs preserve acoustic information better than CIs, children with profound $\mathrm{HI}$ and use HAs in the present study performed worse than those using CIs in Lin and Peng. As the mean aided hearing threshold of participants in the current study (43.4 dB HL) was poorer than that in Lin and Peng's study (30 dB HL) and children with profound HI may not get sufficient amplification at high frequencies [46], there could be some audibility issues with the weaker consonants [47,48]. In addition, cochlear dead regions may restrict the benefits from HAs [49,50]. Therefore, it is not surprising that children with profound HI and fitted with HAs in the current study performed poorer than children with CIs in Lin and Peng [9]. Given that these late CI users were able to perform better than HA users with similar degree of HI, CI seems to be a better option for consonant discrimination.

In quiet, four minimal consonant pairs contrasted by aspiration (i.e., $/ \mathrm{p} /-/ \mathrm{p}^{\mathrm{h}} /, / \mathrm{t} /-/ \mathrm{t}^{\mathrm{h}} /, / \mathrm{t} 6 /-$ $/ \mathrm{t}^{\mathrm{h}} /$ and $/ \mathrm{k} /-/ \mathrm{k}^{\mathrm{h}} /$ ) were easy to discriminate by children with moderate to severe and profound HI. Although few studies have examined the perception of aspiration in Mandarin, research on perception of voicing contrasts may help us gain a better understanding of aspiration perception. Because the aspiration contrast in Mandarin is analogous to the voicing contrast in English. NH listeners mainly rely on the vowel onset time (VOT), the presence of aspiration noise and the pattern of first formant transitions, to perceive voicing contrasts [8]. Revoile et al. [51] indicated that listeners with moderate and severe HI could use both VOT and the presence of aspiration of noise as voicing cues. Holden-Pitt et al. [52] found that six out of 16 children with HI could perceive voicing contrasts and five children perceived voicing contrasts via VOT and one child with HI perceived voicing contrasts correctly via voice-onset characteristics. In Cantonese, Tsui 
and Ciocca [43] found that Cantonese speakers with HI could use the presence of aspiration noise and formant transition information as voicing cues and mainly rely on the formant transition information. Therefore, the discrimination of the four Mandarin aspiration consonant minimal pairs $\left(/ \mathrm{p} /-/ \mathrm{p}^{\mathrm{h}} /, / \mathrm{t} /-/ \mathrm{t}^{\mathrm{h}} /, / \mathrm{t} 6 /-/ \mathrm{t}^{\mathrm{h}} /\right.$ and $\left./ \mathrm{k} /-/ \mathrm{k}^{\mathrm{h}} /\right)$ may partially rely on the difference in VOT, formant transition information and the presence of aspiration noise between two consonants in each pair. Future studies should determine the predominant cues for perceiving Mandarin aspiration contrasts.

The /f/-/x/ contrast was also easy for children with moderate to severe HI to discriminate, as reported in previous studies that labiodental and velar consonants locate at two extremity of oral cavity and therefore, these results are not surprising [53]. Compared with other Mandarin consonants, these phonemes $\left(/ \mathrm{p} /-/ \mathrm{p}^{\mathrm{h}} /, / \mathrm{t} /-/ \mathrm{t}^{\mathrm{h}} /, / \mathrm{t} \mathrm{c} /-/ \mathrm{t}^{\mathrm{h}} /, / \mathrm{k} /-/ \mathrm{k}^{\mathrm{h}} /\right.$ and $\left./ \mathrm{f} /-/ \mathrm{x} /\right)$ are the first to be acquired by children with $\mathrm{NH}[12,45,54]$.

The easy to discriminate consonant minimal pairs from the current study and Lin and Peng [9] were also compared. In the current study, children with moderate to severe HI obtained scores above $90 \%$ for three consonant minimal pairs in quiet (i.e., $/ \mathrm{t} /-/ \mathrm{t}^{\mathrm{h}} /, / \mathrm{f} /-/ \mathrm{x} /$ and $/ \mathrm{t} 6 /-/ \mathrm{t} 6^{\mathrm{h}} /$ ). Lin and Peng [9] also found children with CIs scored three consonant pairs (i.e., /f/-/x/, /t/-/t $/$ and /p/-/m/) above $90 \%$. The two contrastive minimal pairs $/ \mathrm{t} /-/ \mathrm{t}^{\mathrm{h}} /$ and $/ \mathrm{f} /-\mathrm{x} /$ were found being the two easiest in both studies. The performance on the $/ \mathrm{p} /-/ \mathrm{m} /$ pair in the current study $(85 \%)$ was close to that reported in Lin and Peng. However, the $/ \mathrm{t}_{6} /-/ \mathrm{t}^{\mathrm{h}} /$ pair in Lin and Peng yielded $74 \%$ accuracy, which was $16 \%$ lower than that in the current study. The differences in performance could again be due to the above reasons (that is, a discrimination task being easier than an 
identification task, hearing aids provide better speech cues and longer amplification causes better speech perception). Among children with profound HI, no consonant pairs scored above $90 \%$ correct. In other words, children with profound HI and use HAs in the present study performed worse than CI users in Lin and Peng, as discussed above.

\section{Conclusions}

Overall, aspiration seems to be a salient feature for consonant discrimination while consonants acquired later seemed to be more difficult to discriminate in minimal contrastive pairs. The roles of manner and place of articulation are not so clear. The consonant discrimination performance of children with moderate to severe HI was significantly better than that of children with profound HI. However, the performance of children with moderate to severe HI was still not satisfactory. As consonant discrimination of children with profound $\mathrm{HI}$ and fitted with HAs were poorer than those with profound $\mathrm{HI}$ and fitted with CI reported in precious research, CI seems to be a better intervention than HAs for this population. Thus, future studies should examine how the consonant discrimination ability of children with $\mathrm{HI}$ could be improved. As universal newborn hearing screening is gaining popularity in regions outside the main metropolis [55], early intervention and better outcome with amplification are expected. Follow up studies to examine how these factors affect the children with HI should be conducted. Future research should also exam consonant

discrimination ability under different noise types (i.e., babble noise, train noise and café environment). Finally, though the age of first HA fitting and the duration of HA use were not correlated with consonant discrimination ability in children with HAs in the present study, this does not deny the benefits of early amplification. Instead, we should examine in greater details the trajectories of consonant perception. 


\section{Acknowledgments}

We thank all the children who participated in the study. We are grateful to the Hearing Impairment and Rehabilitation Institute of Zhejiang Chinese Medical University in Hangzhou for their cooperation during the data collection period. We also appreciate the statistical advices from Samantha Kar Yan Li. This research was supported by the Faculty Research Fund, administered by the Faculty of Education, the University of Hong Kong as well as the General Research Fund \# 780109, administered by the Hong Kong Research Grants Council (RGC). Parts of this research constituted a Ph.D. dissertation, to be submitted by the first author to the University of Hong Kong. 


\section{References}

[1] I. McLoughlin, Vowel Intelligibility in Chinese, IEEE Trans. Audio. Speech Lang. Process. 18 (1) (2010) $117-125$.

[2] S. L. Phillips, S. J. Richter, D. McPherson, Voiced Initial Consonant Perception Deficits in Older Listeners with Hearing Loss and Good and Poor Word Recognition, J. Speech Lang. Hear. Res. 52 (2009) 118-129.

[3] D. K. Port, T. Z. Burkle, J. H. Lee, Contribution of consonant versus vowel information to sentence intelligibility for young normal-hearing and elderly hearing-impaired listeners, J. Acoust. Soc. Am. 122 (4) (2007) 2365-2375.

[4] D. L. Woods, E. W. Yund, T. J. Herron, Measuring Consonant Identitification in Nonsense Syllables, Words, and Sentences, J. Rehabil. Res. Dev. 47 (3) (2010). 243-260.

[5] K. W. Grant, B. E. Walden, P. F. Seitz, Auditory-visual speech recognition by hearing-impaired subjects: Consonant recognition, sentence recognition, and auditory-visual integration, J. Acoust. Soc. Am. 103 (5) (1998) 2677-2690.

[6] F. Chen, L. L. N. Wong, E. Y. Wong, Assessing the perceptual contributions of vowels and consonants to Mandarin sentence intelligibility, J. Acoust. Soc. Am. 134 (2) (2013) EL178EL184.

[7] S. C. Peng, A. L. Weiss, H. Cheung, Y. S. Lin, Consonant Production and Language Skills in Mandarin-Speaking Children with Cochlear Implants, Arch. Otolaryngol. Head Neck Surg. 130 (2004) 592-597.

[8] R. Kent, C. Read, The acoustic analysis of speech, Singular, San Diego, 1992.

[9] Y. S. Lin, S. C. Peng, Acquisition Profiles of Syllable-initial Consonants in Mandarin-speaking Children with Cochlear Implants, Acta. Otolaryngol. 123 (2003) 1046-1053. 
[10] Z. J. Wu, The calculation of the frequency spectrum and formant in Mandarin vowels and consonants, J. Acoust. 1 (1964) 34-40.

[11] F. Zan, C. L. Liu, The methods, subjects and rules of the phonological development of children, Chin. Special Educ. 3 (2000).

[12] Y. Y. Si, A case study of Mandarin speech acquisition in children, Contemp. Ling. 8 (1) (2006) $1-16$.

[13] X. Zhang, B. Xu, The research of the development of Mandarin consonant perception and production ability, Speech Lang. Hear. Assoc. China. 15 (2000) 1-10.

[14] L. M. Friesen, R. V. Shannon, D. Baskent, X. Wong, Speech recognition in noise as a function of the number of spectral channels: comparison of acoustic hearing and cochlear implants, J. Acoust. Soc. Am. 110 (2) (2001) 1150-1163.

[15] T. Green, A. Faulkner, S. Rosen, Spectral and temporal cues to pitch in noise-excited vocoder simulations of continuous-interleaved-sampling cochlear implants, J. Acoust. Soc. Am. 112 (5) (2002) 2155-2164.

[16] A. E. Vandali, C. Sucher, D. J. Tsang, C. M. McKay, J. W. Chew, H. J. McDermott, Pitch ranking ability of cochlear implant recipients: A comparison of sound-processing strategies, J. Acoust. Soc. Am. 117 (5) (2005) 3126-3138.

[17] E. A. Schorr, F. P. Roth, N. A. Fox, A comparison of the speech and language skills of children with cochlear implants and children with normal hearing, Commun. Disord. Quarterly. 29 (4) (2008) 195-210.

[18] N. P. Erber, Auditory, visual, and Auditory-visual Recognition of consonants by children with normal and impaired hearing, J. Speech Hear. Res. 15 (1972) 413-422.

[19] D. Han, B. Liu, N. Zhou, X. Chen, Y. Kong, H. Liu, et al., Lexical Tone Perception with 
HiResolution and HiResolution 120 Sound-Processing Strategies in Pediatric MandarinSpeaking Cochlear Implant Users, Ear Hear. 30 (2) (2009) 169-177.

[20] Y. Chen, L. L. N. Wong, F. Chen, X. Xi, Tone and sentence perception in young Mandarinspeaking children with cochlear implants, Int. J. Pediatr. Otorhinolaryngol. 78 (11) (2014) 1923-1930.

[21] N. Zhou, J. Huang, X. Chen, L. Xu, Relationship between tone perception and production in prelingually deafened children with Cochlear Impalnts, Otol. Neurotol. 34 (2013) 499-506.

[22] S. H. Oh, C. H. Kim, E. J. Kang, D. S. Lee, H. J. Lee, S. O. Chang, et al., Speech perception after cochlear implantation over a 4-year time period, Acta. Otolaryngol. 123 (2) (2003) 148153.

[23] World Health Organization, Primary ear and hearing care training resource. Advanced level, Geneva: World Health Organization, 2006.

[24] M. S. Hiskey, Hiskey-Nebraska Test of Learning Aptitude, Lincoln, NE: College View Printers, 1966.

[25] X. Yang, C. Qu, X. Sun, F. Zhu, J. Wang, Norm revision of H-NTLA for children from 3 to 7 years old in China, Chin. J. Clin. Psychol. 19 (2) (2011) 195-197.

[26] B. U. Watson, D. E. Goldgar, A note on the use of the Hiskey-Nebraska Test of learning aptitude with deaf children, Lang. Speech Hear. Serv. Sch. 16 (1985) 53-57.

[27] Y. Zheng, Z. L. Meng, K. Wang, Y. Tao, K. Xu, S. D. Soli, Development of the Mandarin Early Speech Perception Test: children with normal hearing and the effects of dialect exposure, Ear Hear. 30 (5) (2009) 600-612.

[28] M. N. Somers, Speech Perception Abilities in Children with Cochlear Implants or Hearing Aids, Am. J. Otology. 12 (1991) 174-178. 
[29] J. B. Tomblin, L. Spencer, S. Flock, R. Tyler, B. Gantz, A Comparison of Language Achievement with Cochlear Implants and Children Using Hearing Aids, J. Speech Lang. Hear. Res. 42 (1999) 497-511.

[30] K. M. Van Lierde, B. M. Vinck, N. Baudonck, E. De Vel, I. Dhooge, Comparison of the overall intelligibility, articulation, resonance, and voice characteristics between children using cochlear implants and those using bilateral hearing aids: A pilot study, Int. J. Audiol. 44 (8) (2005) 452-465.

[31] N. Erber, Auditory training, Alexander Graham Bell Association for the Deaf, Washington, DC, 1982.

[32] X. S. Shen, M. Lin, A Perceptual study of Mandarin Tone 2 and 3, Lang. speech. 34 (2) (1991) 145-156.

[33] H. Dillon, The effect of test difficulty on the sensitivity of speech discrimination tests, J. Acoust. Soc. Am. 73 (1) (1983) 336-344.

[34] M. E. Lutman, Hearing disability in the elderly, Acta. Otolaryngol. Suppl. 476 (1990) 239248.

[35] S. Jerger, Current State of Knowledge: Perceptual Processing by Children with Hearing Impairment, Ear Hear. 28 (6) (2007) 754-765.

[36] D. Byrne, A. Parkinson, P. Newall, Hearing aid gain and frequency response requirements for the severely/profoundly hearing impaired, Ear Hear. 11 (1) (1990) 40-49.

[37] A. Snik, G. Hombergen, Hearing aid fitting of preschool and primary school children: an evaluation using the insertion gain measurement, Scand. Audiol. 22 (4) (1993) 245-250.

[38] A. F. Snik, A. M. Vermeulen, C. P. Geelen, J. P. Brokx, P. Van Den Broek, Speech Perception 
Performance of Children with a Cochlear Implant Compared to that of Children with Conventional Hearing Aids: II. Results of Prelingually Deaf Children, Acta. Otolaryngol. 117 (5) (1997) 755-759.

[39] S. C. Peng, J. B. Tomblin, H. Cheung, Y. S. Lin, L. S. Wang, Perception and Production of Mandarin Tones in Prelingually Deaf Children with Cochlear Implants, Ear Hear. 25 (3) (2004) 251-264.

[40] S. Zhu, L. L. N. Wong, F. Chen, Tone identification in Mandarin-speaking children with profound hearing impairment, Int. J. Pediatr. Otorhinolaryngol. 78 (2014) 2292-2296

[41] C. M. Connor, H. K. Craig, S. W. Raudenbush, K. Heavner, T. A. Zwolan, The age at which young deaf children receive cochlear implants and their vocabulary and speech-production growth: is there an added value for early implantation? Ear hear. 27 (6) (2006) 628-644.

[42] J. Bamford, E. Saunders, Hearing impairment, auditory perception and language disability, Child. Lang. Teach. Therap. 8 (2) (1992) 227-228.

[43] Y. H. Tsui, V. Ciocca, Perception of aspiration and place of articulation of Cantonese initial stops by normal and sensorineural hearing-impaired listeners, Int. J. Lang. Commun. Disord. 35 (4) (2000) 507-525.

[44] Y. Y. C. Tse, Perception of Cantonese Initial Consonants in Single Words in Noise, The University of Hong Kong, Hong Kong, 2014.

[45] W. Li, H. Zhu, B. Dodd, Phonological acquisition in Mandarin-speaking children, Psychol. Bull. 2 (2000).

[46] C. W. Turner, K. J. Cummings, Speech audibility for listeners with high-frequency hearing loss, Am. J. Audiol. 8 (1) (1999) 47.

[47] A. A. Montgomery, R. A. Edge, Evaluation of two speech enhancement techniques to improve 
intelligibility for hearing-impaired adults, J. Speech Lang. Hear. Res. 31 (3) (1988) 386-393.

[48] E. Kennedy, H. Levitt, A. C. Neuman, M. Weiss, Consonant-vowel intensity ratios for maximizing consonant recognition by hearing-impaired listeners, J. Acoust. Soc. Am. 103 (2) (1998) 1098-1114.

[49] B. C. Moore, Dead regions in the cochlea: Diagnosis, perceptual consequences, and implications for the fitting of hearing aids, Trends Amplification, 5 (1) (2001) 1-34.

[50] J. K. Niparko, (Ed.), Cochlear implants: principles \& practices, Lippincott Williams \& Wilkins, 2009.

[51] S. Revoile, J. M. Pickett, L. D. Holden-Pitt, D. Talkin, F. D. Brandt, Burst and transition cues to voicing perception for spoken initial stops by impaired-and normal-hearing listeners, J. Speech Lang. Hear. Res. 30 (1) (1987) 3-12.

[52] L. D. Holden-Pitt, V., Hazan, S. G. Revoile, D. M. Edward, J. Droge, Temporal and spectral cue use for initial plosive voicing perception by hearing-impaired children and normalhearing children and adults, Int. J. Lang. Commun. Disord. 30 (4) (1995) 417-434.

[53] Z. Liu, X. Bu, G. Xing, L. Lu, A preliminary study of a hearing screening model for newborn, Chin. J. Otorhinolaryngol. 36 (4) (2001) 292-294.

[54] J. F. Hou, Some queations on formulating the speech audiometry lists of Mandarin deaf children from two years old to four years old, Capital Normal University, Beijing, 2012.

[55] S. J. Howard, B. C. Heselwood, Learning and teaching phonetic transcription for clinical purposes, Clin. Ling. Phonetics. 16 (5) (2002) 371-401. 


\section{Figure legends}

Figure 1. Mean consonant discrimination scores in quiet and in five noisy conditions, obtained on children with different levels of $\mathrm{HI}$ and fitted with HAs. The error bars denote \pm 1 SEM.

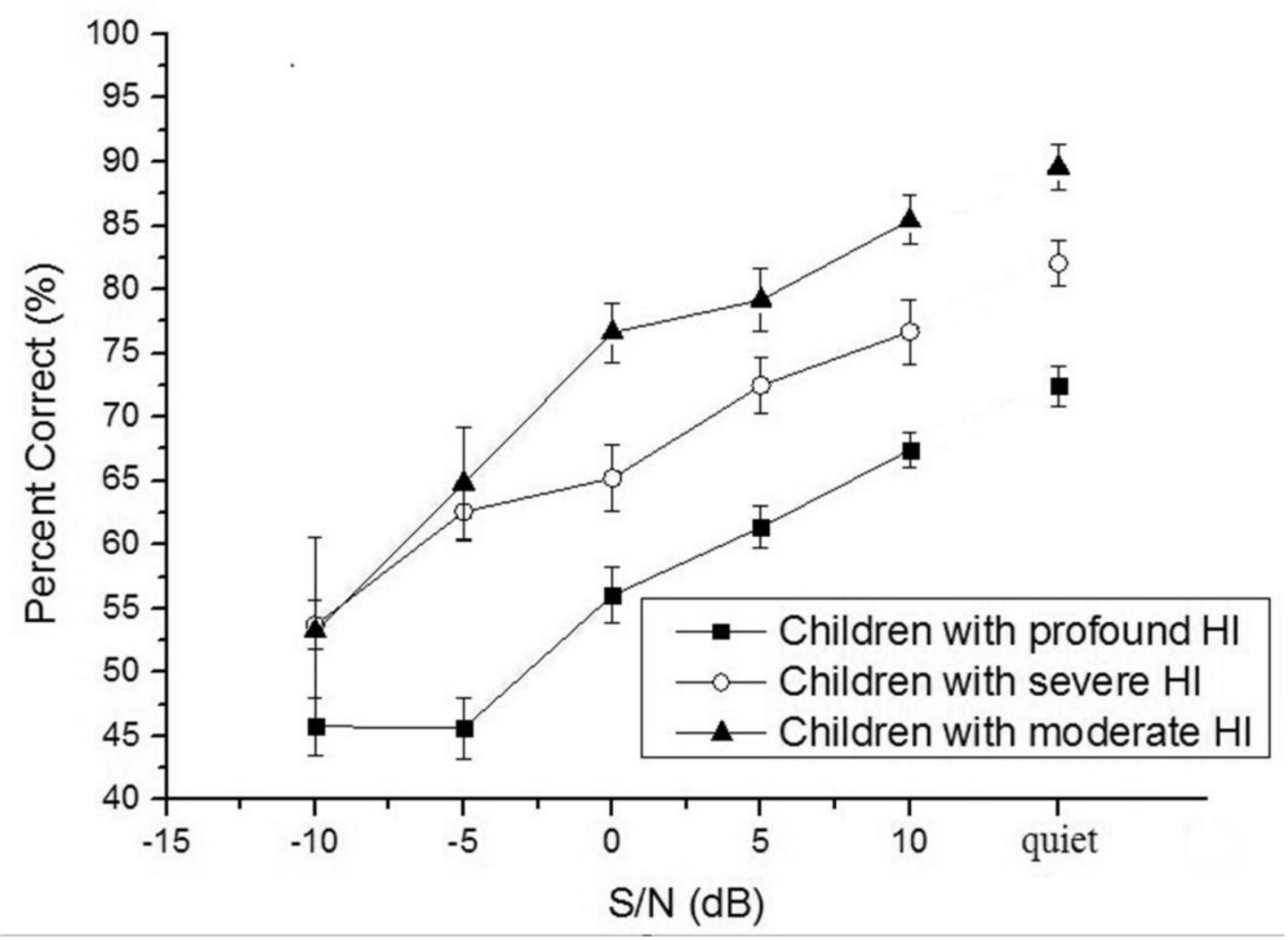


Figure 2. Mean scores obtained with the minimal pairs in quiet in children with profound HI. The minimal pairs that yielded scores that deviated by more than $+/-1$ standard deviation (SD) from the overall mean.

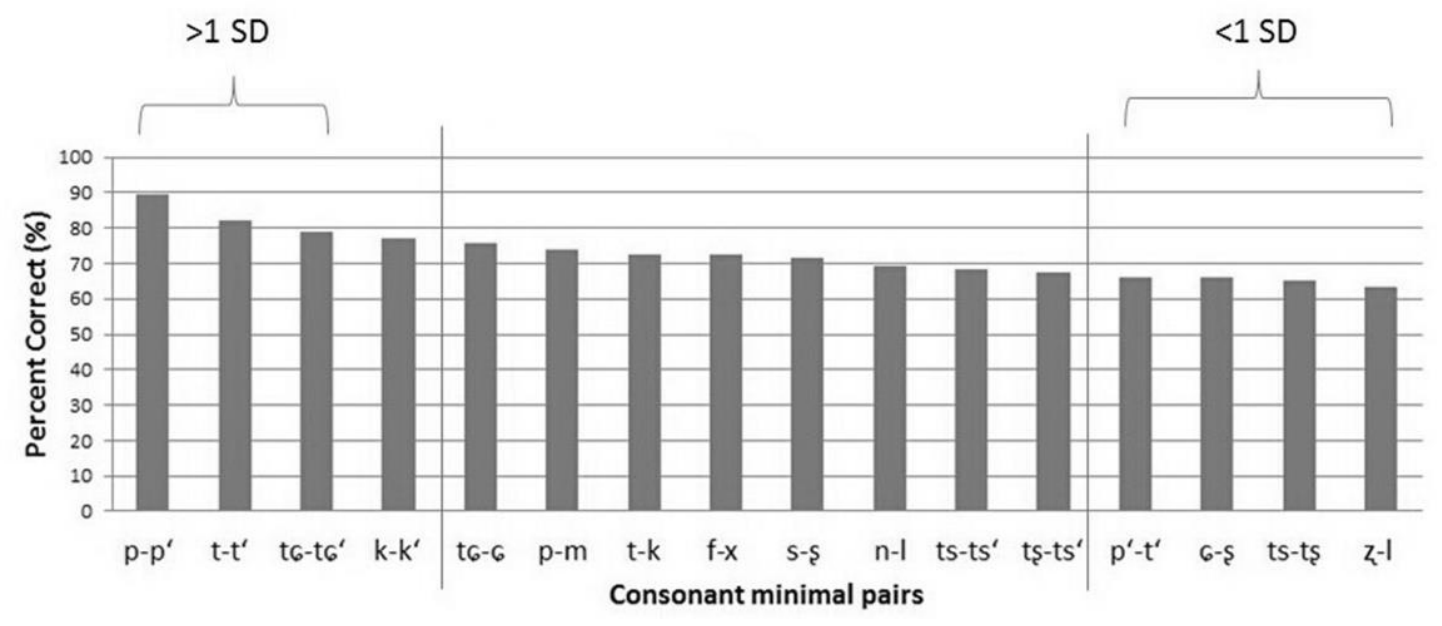


Figure 3. Mean scores obtained with the minimal pairs in quiet in children with moderate to severe HI. The minimal pairs that yielded scores that deviated by more than $+/-1$ standard deviation (SD) from the overall mean

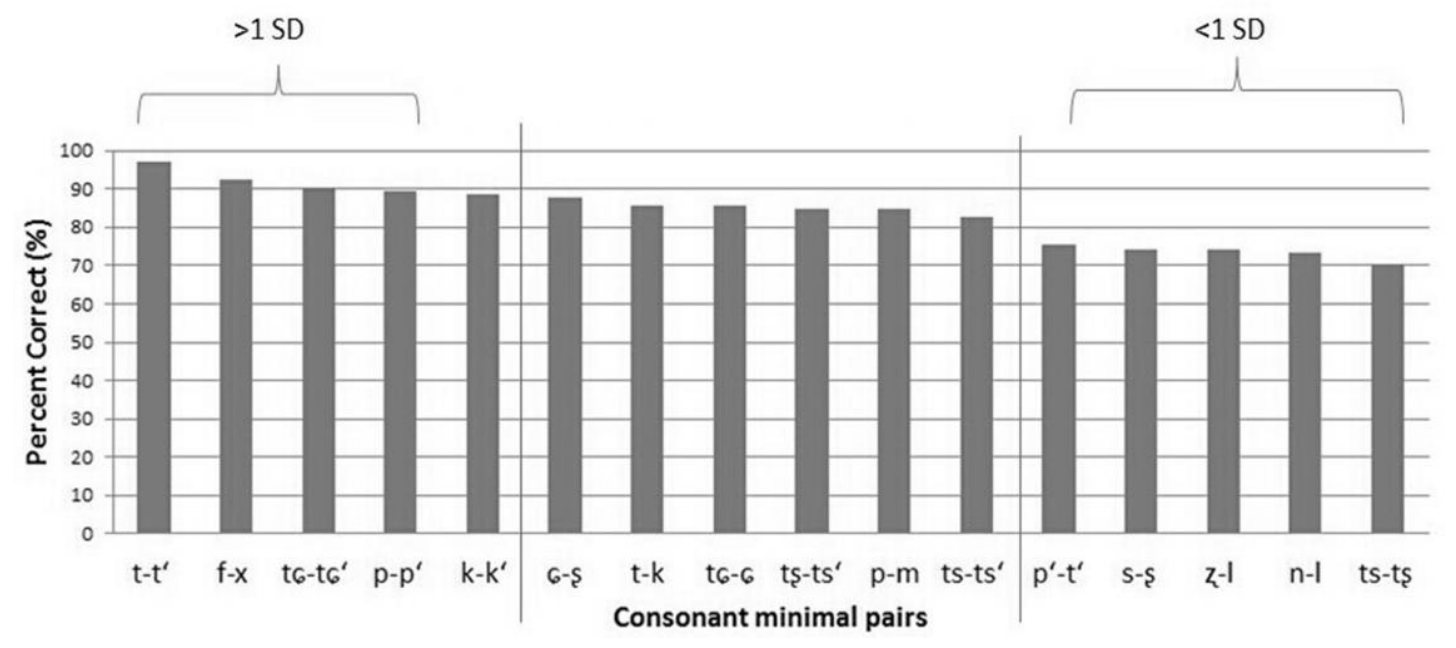


Figure 4. Mean consonant discrimination scores in quiet and in six noisy conditions across all $\begin{array}{llllllll}\text { subjects. } & \text { The } & \text { error } & \text { bars } & \text { denote } & \pm & & \text { SEM. }\end{array}$

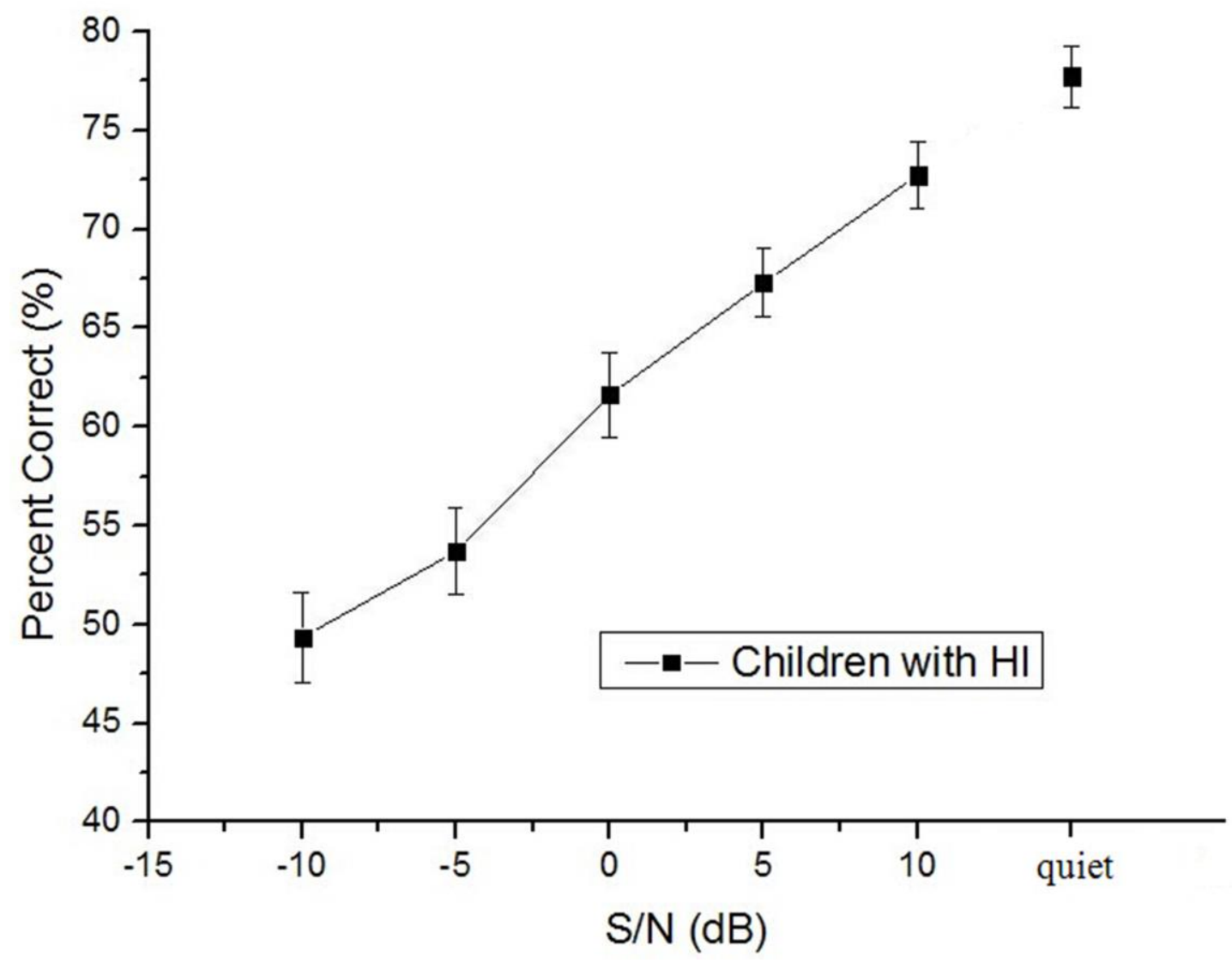


Table 1

Demographics of children participated in the current study (total $N=76$ ). Range of data is listed in the top row and means and SDs are listed in the bottom row for each subject group.

\begin{tabular}{|c|c|c|c|c|c|}
\hline Group & $\mathrm{N}$ & $\begin{array}{l}\text { Mean } \\
\text { Hearing } \\
\text { threshold } \\
(\mathrm{dB} \mathrm{HL})\end{array}$ & $\begin{array}{l}\text { Chronological } \\
\text { age } \\
\text { (years;months) }\end{array}$ & $\begin{array}{l}\text { Age of first HA fitting } \\
\text { (years;months) }\end{array}$ & $\begin{array}{l}\text { Duration of HA use } \\
\text { (years;months) }\end{array}$ \\
\hline Profound & 41 & $\begin{array}{l}81.3-110 \\
\text { (Mean }\end{array}$ & $\begin{array}{l}5 ; 4-12 ; 6 \\
\text { (Mean 9;0, SD }\end{array}$ & $\begin{array}{l}0 ; 6-11 ; 0 \\
(\text { Mean 2;8, SD 2;1) }\end{array}$ & $\begin{array}{l}1 ; 0-11 ; 5 \\
(\text { Mean 6;4, SD 2;4) }\end{array}$ \\
\hline Severe & 26 & $\begin{array}{l}\text { 61.3-80 } \\
\text { (Mean }\end{array}$ & $\begin{array}{l}6 ; 1-12 ; 4 \\
\text { (Mean 9;0, SD }\end{array}$ & $\begin{array}{l}1 ; 0-5 ; 4 \\
\text { (Mean 4;6, SD 2;3) }\end{array}$ & $\begin{array}{l}1 ; 0-7 ; 10 \\
\text { (Mean 4;6, SD 2;2) }\end{array}$ \\
\hline Moderate & 9 & $\begin{array}{l}\text { 41.3- } \\
\text { (Mean }\end{array}$ & $\begin{array}{l}5 ; 0-11 ; 9 \\
\text { (Mean 8;6, SD }\end{array}$ & $\begin{array}{l}0 ; 6-8 ; 1 \\
(\text { Mean 4;8, SD 2;6) }\end{array}$ & $\begin{array}{l}0 ; 1-6 ; 3 \\
(\text { Mean 3;6, SD 2;2) }\end{array}$ \\
\hline
\end{tabular}


Table 2

Unaided and aided hearing thresholds of children participated in the current study $(N=76)$.

Unaided hearing threshold

Aided hearing threshold

Group

$($ Mean \pm SD dB HL)

$($ Mean \pm SD dB HL)

Left ear Right ear Better ear Left ear Right ear Better ear

Profound $\quad 96.0 \pm 9.5 \quad 97.7 \pm 9.7 \quad \mathbf{9 2 . 9} \pm \mathbf{8 . 6} \quad 46.1 \pm 6.8 \quad 47.2 \pm 7.5 \quad \mathbf{4 3 . 4} \pm \mathbf{6 . 9}$

$\begin{array}{lllllll}\text { Severe } & 73.9 \pm 7.8 & 71.8 \pm 7.5 & \mathbf{6 9 . 9} \pm \mathbf{5 . 8} & 38.1 \pm 7.8 & 40.0 \pm 6.7 & \mathbf{3 5 . 7} \pm \mathbf{6 . 7}\end{array}$

Moderate $\quad 54.7 \pm 7.0 \quad 71.9 \pm 15.5 \quad \mathbf{5 2 . 6} \pm \mathbf{6 . 4} \quad 32.6 \pm 5.7 \quad 39.0 \pm 7.7 \quad \mathbf{3 1 . 1} \pm \mathbf{5 . 3}$

Note: unaided and aided hearing thresholds represent averages at 500, 1000, 2000 and $4000 \mathrm{~Hz}$. 
Table 3

The 16 pairs of target consonants using in the current study

\begin{tabular}{|c|c|c|}
\hline Tested consonants in IPA & Test stimuli in IPA & Test stimuli in Chinese \\
\hline$/ \mathrm{t} 6 /-/ 6^{\mathrm{h}} /$ & $\mathrm{t} 6 \mathrm{in}-\mathrm{t}^{\mathrm{h}} \mathrm{in}$ & (晶一轻) \\
\hline$/ \mathrm{ts}^{\mathrm{h}} /-/ \mathrm{ts}^{\mathrm{h}} /$ & 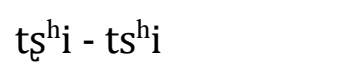 & （翅-次） \\
\hline$/ \mathrm{ts} /-/ \mathrm{ts}^{\mathrm{h}} /$ & $\mathrm{tsi}-\mathrm{ts}^{\mathrm{h}} \mathrm{i}$ & （姿-疵） \\
\hline /s/-/s/ & san - san & (三-山 ) \\
\hline$/ \mathrm{p}^{\mathrm{h}} /-/ \mathrm{t}^{\mathrm{h}} /$ & $\mathrm{p}^{\mathrm{h}} \mathrm{au}-\mathrm{t}^{\mathrm{h}} \mathrm{au}$ & （抛-滔） \\
\hline /ts/-/ts/ & tsu - tşu & （租一朱） \\
\hline$/ \mathrm{p} /-/ \mathrm{p}^{\mathrm{h}} /$ & pan - $\mathrm{p}^{\mathrm{h}} \mathrm{an}$ & （斑-潘） \\
\hline$/ \mathrm{t} /-/ \mathrm{t}^{\mathrm{h}} /$ & $\tan -\mathrm{t}^{\mathrm{h}} \mathrm{an}$ & （丹-贪） \\
\hline$/ \mathrm{k} /-/ \mathrm{k}^{\mathrm{h}} /$ & $\mathrm{kan}-\mathrm{k}^{\mathrm{h}} \mathrm{an}$ & （甘一刊） \\
\hline /f/-/x/ & fan - xan & （番-酣） \\
\hline$/ \mathrm{t}_{6} /-/ 6 /$ & $\mathrm{t} 6 \mathrm{i}-6 \mathrm{i}$ & (寄一系) \\
\hline$/ \mathrm{t} /-/ \mathrm{k} /$ & tou - kou & （兒一勾） \\
\hline$/ 6 /-/ \mathrm{s} /$ & $6 i-s i$ & （稀一施） \\
\hline$/ \mathrm{n} /-/ \mathrm{l} /$ & niou -liou & （妞-溜） \\
\hline$/ \mathrm{z} /-/ \mathrm{l} /$ & zy -ly & (热-乐) \\
\hline$/ \mathrm{p} /-/ \mathrm{m} /$ & pən -mən & （奔-闷） \\
\hline
\end{tabular}


Table 4

Results of backward stepwise multiple linear regression analysis on consonant discrimination both in quiet and in noise. Only unaided hearing thresholds was a significant factor; the valuables aided hearing thresholds, age of first HA fitting and duration of HA use were excluded.

Std.

\begin{tabular}{llllllllll} 
Conditions & Tests & & B & Error & Beta & $R$ square & $r$ & $p$ \\
\hline \multirow{2}{*}{ quiet } & \multirow{2}{*}{ Consonant } & constant & 107.75 & 5.38 & & & & & \\
& & HI level & -0.47 & 0.07 & - & $\mathbf{0 . 3 0 4}$ & 0.55 & $<0.00$ \\
\multirow{2}{*}{$10 \mathrm{~dB}$ S/N } & Consonant & constant & 101.51 & 5.85 & & & & \\
& & & HI level & -0.36 & 0.07 & - & $\mathbf{0 . 2 5 4}$ & 0.50 & $<0.00$ \\
\hline
\end{tabular}

